DARIA WRONA

ORCID 0000-0002-5493-463X

Uniwersytet im. Adama Mickiewicza

$w$ Poznaniu

\title{
COSPLAY - ZNACZENIE FENOMENU W RELACJACH UCZESTNICZEK
}

\begin{abstract}
AвSTRACt. Wrona Daria, Cosplay - znaczenie fenomenu w relacjach uczestniczek [Cosplay - the Significance of the Phenomenon in Female Participants' Accounts]. Studia Edukacyjne nr 56, 2020, Poznań 2020, pp. 385-399. Adam Mickiewicz University Press. ISSN 1233-6688. DOI: 10.14746/se.2020.56.21

Cosplay is a poorly understood phenomenon related to popular culture. Currently, however, it is slowly attracting the interest of an increasing number of fields of science, such as sociology, psychology or pedagogy. The following article will present the theoretical foundations and research on the role of cosplay in the life of female cosplayers. Focusing on the subjects, I touched upon the issues of interpersonal interactions, interests and skills, social perception of cosplay, problems related to the preparation of costumes, and the impact of cosplay on identity development.
\end{abstract}

Key words: cosplay, identity, youth, pop culture

\section{Wstęp}

Cosplay stanowi jeszcze słabo poznane zjawisko, związane z kulturą popularną. Obecnie jednak zaczyna być postrzegane przez coraz większą liczbę dziedzin nauki, jak socjologia, psychologia, czy pedagogika.

$\mathrm{W}$ poniższym artykule zostały przedstawione podstawy teoretyczne oraz badania odnośnie roli cosplayu w życiu cosplayerek. Skupiając się na badanych, poruszyłam problematykę interakcji międzyludzkich, zainteresowań i umiejętności, społecznego odbioru cosplayu, problemów związanych z przygotowaniem strojów oraz wpływu cosplayu na kształtowanie tożsamości.

\section{Czym jest cosplay}

Termin cosplay pochodzi od japońskiego słowa kospure, które stanowi kombinację słów „,costume” - コス - i „play” - プレ.Zjawisko to dotyczy prze- 
bierania się za postaci pochodzące $z$ kultury popularnej ${ }^{1} \mathrm{i}$ jest związane bezpośrednio z tak zwanym fandomem, czyli „,przestrzenią entuzjastów" ${ }^{\prime 2}$. Nawiązując do L. Duchesne, fandom może być rozumiany również jako „(...) szczególny rodzaj wystąpienia, eksplorowany na rozmaite sposoby przez jego członków, którzy poszukują tożsamości i nadają mu własnych warstw znaczeniowych"3. Oznacza to, iż fandom dotyczy fanów poszczególnych postaci/uniwersów/gatunków i tak dalej, którzy poprzez swoją aktywność nadają mu indywidualne znaczenie; dochodzi tutaj także do poszukiwania tożsamości oraz specyficznej działalności w obrębie grup osób zainteresowanych tym samym co jednostka. Może to być ta sama postać, ten sam serial, ta sama książka.

Oprócz kostiumów, cosplay odnosi się również do takich aktywności, jak maskarady, karaoke, pozowanie do zdjęć wraz z innymi otaku oraz do odgrywania zachowania, jak postaci z anime, mangi, czy gier komputerowych. Theresa Winge nawiązuje w swoim artykule do tego, iż termin cosplay pochodzi od "costume" i ",role-play”, nie zaś od samego "play"4. Termin otaku można zrozumieć $\mathrm{w}$ tym kontekście dwojako ${ }^{5}$ :

1) w Ameryce Północnej nawiązuje on do fana mangi i anime, jednak rozumianego jako ekstremum/skrajność, a więc kojarzonego pejoratywnie;

2) w Japonii pojmowany jest jako zwrot honorowy, używany w stosunku do bliskiego przyjaciela.

Na potrzeby artykułu otaku rozumiane jest zgodnie ze znaczeniem przyjętym w Ameryce Północnej.

Zjawisko, jakim jest cosplay umożliwia uczestnikom nabycie przyjemnych doświadczeń, znaczących wspomnień oraz poczucia spełnienia. Oprócz tego jest także formą eskapizmu, dzięki któremu cosplayerzy przenoszą się z rzeczywistości do własnych wykreowanych światów. Cosplay stanowi również formę transformacji roli/tożsamości ze "zwyczajnej osoby” do „superbohatera", z "odgrywającego rolę" do "aktora” oraz z "dorosłości” do "dzieciństwa" ${ }^{\prime \prime}$. Ze względu na eskapizm, otoczenie społeczne i aktywność uczestników w fandomie, cosplay powoduje wzrost samooceny cosplayerów i wiązany jest z lepszym samopoczuciem, ucieczką od codziennych stresorów oraz możliwością wyrażania siebie ${ }^{7}$.

${ }^{1}$ A. Lotecki, Cosplay Culture: The Development of Interactive and Living Art Throught Play, 2012, s. iii.

${ }^{2}$ Zob. M. Ito, D. Okabe, I Tsuji, Fandom Unbound: Otaku Culture in a Connected World, 2012.

${ }^{3}$ Duchesne, 2005, za: O. Rahman, "Cosplay": Imaginative Self and Performing Identity, [w:] Fashione Theory, The Journal of Dress Body \& Culture, 2012, s. 318.

${ }^{4} \mathrm{~T}$. Winge, Costuming the Imagination: Origins of Anime and Manga Cosplay, Mechademia, 2006, s. 65 .

5 Tamże, s. 75.

${ }^{6}$ O. Rahman, "Cosplay": Imaginative Self, s. 317-318.

7 K.C. Gerbasi i in., "Coming Out" as an Anime Fan: Cosplayers in the Anime Fandom, Fan Disclosure, and Well-Being, The Phoenix Papers, 2018, s. 2. 
Cosplay we współczesnym kontekście subkulturowym używany jest najczęściej do opisania aktywności, polegającej na przebieraniu się i zachowywaniu, jak postaci z mangi, anime, tokusatsu (filmy lub programy telewizyjne, które cechują się efektami specjalnymi), gier komputerowych, sci-fi (science fiction) i grup muzycznych. Dzięki powiązaniu z kulturą popularną, może zostać skategoryzowany jako pochodzący z fantastyki, romansu, sci-fi, mitologii, fetyszystyczny, słodki, gotycki i tym podobne ${ }^{8}$. Jednak tak zwane Lolity nie są klasyfikowane jako cosplay, ponieważ nie dochodzi do odgrywania roli, które w tej aktywności są kluczowe. Lolity uznawane są za odrębną subkulturę?.

Oryginalny model definiuje subkulturę jako spoistą grupę o wspólnej historii, etniczności oraz podobnym statusie socjoekonomicznym w społeczeństwie, co nie do końca ma swoje odzwierciedlenie $\mathrm{w}$ przypadku cosplayu ${ }^{10}$. O ile doświadczenia i historia są poniekąd wspólne, o tyle cosplayerzy mają różnorodny status społeczno-ekonomiczny, a grupa jest niejednorodna etnicznie. Dlatego uznaje się, iż należą do większej wspólnoty fanów fikcji, fantastyki, gier wideo i tak zwanego Japanimation (termin odnoszący się do japońskiej animacji, mangi i gier wideo), czyli fandomu nerdów $w^{11}$.

Natomiast, biorąc pod uwagę, iż „,subkultura odnosi się do odrębnej kulturowo grupy, która istnieje jako identyfikowalny element wewnątrz większej, bardziej skomplikowanej grupy społecznej"12, cosplay może zostać zdefiniowany jako subkultura, ponieważ charakteryzuje się cechami umożliwiającymi jego identyfikację na tle większej wspólnoty, jaką są fani kultury popularnej.

Theresa Winge wyodrębniła w swoim artykule cztery komponenty cosplayu, na które składają się: cosplayer, otoczenie społeczne, postać i role-play oraz kostium $^{13}$. Elementy te łączą się i podlegają wzajemnym interakcjom. Pomimo iż zostały wyodrębnione na potrzeby cosplayu dotyczącego mangi i anime, ich uniwersalność pozwala opisać również pozostałe kategorie ${ }^{14}$.

Ze względu na rosnącą popularność w XXI wieku oraz globalizację, która umożliwia wymianę zdjęć, materiałów i doświadczeń, cosplay staje się coraz bardziej skomplikowany. Osoby zajmujące się wcielaniem w postaci spędzają niezliczone liczby godzin na wytwarzaniu kostiumów. Poświęcają również wiele środków finansowych i sił, aby jak najbardziej upodobnić się do wy-

${ }^{8}$ O. Rahman, "Cosplay": Imaginative Self, s. 318.

9 Tamże.

${ }^{10}$ Hebdige, 1979, za: N.L. Hill, Embodying Cosplay: Fandom Communities in the USA, 2017, s. 4.

${ }_{11}$ Tamże, s. 4.

12 O. Rahman, "Lolita": Imaginative Self and Elusive Consumption, [w:] Fashion Theory, The Journal of Dress Body \& Culture, 2011, s. 9.

${ }^{13}$ T. Winge, Costuming the Imagination, s. 67-73.

${ }^{14}$ Zob.: D. Wrona, Cosplay a role-play, [w:] Nauczyciel i uczeń w przestrzeni społecznej, Kraków 2019. 
branych bohaterów. Popularność tego zjawiska oraz związane z nim komponenty sprawiają, iż cosplay jest zjawiskiem podkreślającym kreatywność jednostki. Reprodukowanie kostiumów, wykonywanie sesji fotograficznych, czy przygotowywanie występów na konkursy cosplay wiąże się z pomysłowością, improwizacją i wykraczaniem poza schematy ${ }^{15}$. Ukazuje również umiejętności cosplayerów w różnych aspektach, takich jak zdolności interpersonalne, szycie, malowanie, czy gra aktorska.

Biorąc pod uwagę role-play jako jeden z centralnych aspektów cosplayu, wyodrębniłam cztery rodzaje doboru postaci do wcielenia się $\mathrm{w}$ rolę: bohater pozytywny, bohater negatywny, bohater tła oraz bohater ambiwalentny ${ }^{16}$. Wybór jest sprawą indywidualną każdego cosplayera, a postać powinna zostać odegrana w taki sposób, aby była jak najbliższa oryginałowi. Nie stanowi to jednak nadrzędnej zasady, ponieważ nie wszyscy cosplayerzy są co do tego aspektu zgodni.

Analizując literaturę oraz odnosząc się do własnych doświadczeń i obserwacji, ujęłam cosplay jako

(...) aktywność polegającą przede wszystkim na wcielaniu się w wybraną postać pochodzącą z kultury popularnej; niejednokrotnie dochodzi tutaj do odgrywania zachowania i charakteru, utożsamiania się z nią. Podstawę stanowi kostium oraz makijaż, które upodabniają nas do danego bohatera i pozwalają stworzyć iluzję obcowania z nim innym ludziom wokół. Często jest również wyrazem przynależności do danej grupy lub fandomu ${ }^{17}$.

Definicja ta zawiera w sobie nie tylko główne komponenty wyodrębnione przez Winge. Zwraca również uwagę na przynależność do grupy i w sposób bezpośredni odnosi się do odgrywania roli.

\section{Metodologia}

Zrealizowane badania jakościowe ${ }^{18}$ miały na celu uzyskanie wiedzy na temat charakteru i dynamiki zjawiska cosplayu. Zastosowanym podejściem badawczym było zbiorowe studium przypadku ${ }^{19}$, a metodą zbierania danych

${ }^{15}$ Zob.: C. Langsford, Cosplay in Australia: (Re)creation and Creativity Assemblage and Negotiation in a Material and Performative Practice, Adelaide 2014.

${ }^{16}$ Zob.: D. Wrona, Cosplay a role-play.

${ }_{17}$ D. Wrona, Cosplay jako fenomen kulturowy. Konteksty pedagogiczne i społeczno-kulturowe (praca magisterska), Poznań 2018.

${ }_{18}$ Tamże, s. 85-97 i 105-133.

${ }^{19}$ E. Babbie, Badania spoteczne w praktyce, Warszawa 2004, s. 320-322. 
- wywiad narracyjny, częściowo ustrukturyzowany ${ }^{20}$. Na potrzeby badań przeprowadzono cztery wywiady, które następnie zostały poddane anali$z^{21}$. Wywiady były nagrywane, następnie dokonano ich transkrypcji, a na koniec - kodowania uzyskanych danych.

Badaniem objęto kwestie związane z postrzeganiem zjawiska cosplayu przez cztery cosplayerki.

Główny problem badawczy został sformułowany w postaci pytania: Jak badane postrzegają rolę cosplayu w swoim życiu?

Problemy szczegółowe natomiast określono jako próbę uzyskania odpowiedzi na następujące pytania:

1. Jak badane postrzegają subkulturę cosplayu?

2. Jakie znaczenie badane przypisują cosplayowi w rozwoju zainteresowań i umiejętności?

3. Jak cosplay jest odbierany społecznie?

4. Z jakimi trudnościami przy wykonywaniu kostiumów spotykają się osoby zajmujące się cosplayem?

5. Jak badane postrzegają rolę cosplayu dla poczucia własnej tożsamości?

Podczas badań, za pomocą wyboru celowego, zwrócono się do młodych kobiet (przedział wieku od 20. do 27. roku życia) zajmujących się cosplayem. Każda z nich wykazywała inny poziom zaangażowania i doświadczenia. Poszukiwanie osób do badania odbywało się poprzez media społecznościowe oraz spotkania organizowane dla osób zainteresowanych cosplayem.

Osoby badane:

W., 24 lata, studentka ochrony środowiska, wykształcenie średnie, mieszkająca w Poznaniu, pochodząca ze wsi; posiadająca wiele zainteresowań (rysunek, malowanie, granie w gry, przerabianie ubrań, komiksy, filmy, chodzenie do kina itp.).

T., 27 lat, wytwórca rekwizytów, wykształcenie wyższe niepełne, pochodząca i mieszkająca w Stanach Zjednoczonych; na co dzień wykonuje kostiumy i rekwizyty oraz gra w gry i ogląda anime.

A., 20 lat, studentka filologii polskiej, wykształcenie średnie, mieszkająca w Szczecinie, pochodząca z miasteczka (ok. 10 tys. mieszkańców); interesuje się szyciem i wykonywaniem kostiumów, literaturą piękną, słuchaniem i komponowaniem muzyki (gra na keyboardzie) oraz czytaniem i tworzeniem poezji.

L., 21 lat, prowadzi własną działalność gospodarczą, wykształcenie średnie, mieszkająca i pochodząca z Poznania; zajmuje się domem, firmą, pływaniem, muzyką i cosplayem.

${ }^{20}$ T. Pilch, T. Bauman, Zasady badań pedagogicznych Strategie ilościowe i jakościowe, Warszawa 2001, s. 327-331.

${ }^{21}$ E. Babbie, Badania spoteczne w praktyce, s. 342-353. 


\section{Analiza wyników badań}

\section{Postrzeganie subkultury cosplayu}

Subkultura cosplayerów pojmowana jest jako zróżnicowana i pełna napięć; tylko jedna osoba wypowiadała się o niej jednoznacznie pozytywnie, reszta mówiła o dziejących się wewnątrz dramach i hejtach oraz o zaciętej rywalizacji. Jedna osoba zwróciła uwagę, iż cosplayerzy są zróżnicowani sami w sobie:

„Jest petno dram i hejtów, ale sa jeszcze osoby, które sa normalne, że tak powiem" (W., 24 lata).

„Sądzę, że w środku subkultury cosplayu znajduje się wiele innych matych subkultur. Niektórzy cosplayerzy skupiaja się na odgrywaniu, inni na wytwarzaniu, jeszcze inni na fotografii, a pozostali po prostu kupuja kostiumy $i$ je nosza. Każdy $z$ nas ma własny sposób na cosplay. Wszyscy jesteśmy różni, ale każdy z nas przychodzi razem wykonywać cosplay, tworzyć sztukę i wyrażać zainteresowanie naszym fandomem. Jeśli byłaby jedna specyficzna kultura dla cosplayu, to myślę, że byłaby to raczej subkultura nerdów/geeków, ale z domieszką sztuki" (T., 27 lat).

„Przyjazna. Ludzie się wspieraja, chociaż widać to po moich kontaktach z Juleczka, która mi często pomaga w robieniu cosplayów i craftowaniu różnych broni. Także jesteśmy taka subkultura, która właśnie się wspiera. To nie jest tak, że np. rywalizujemy ze soba kto jest lepszy, że tutaj mi wychodzi lepiej robienie miecza, a tobie lepiej wychodzi robienie topora, więc rywalizujmy ze soba kto ma lepsze doświadczenie, kto lepiej stworzy dana broń. Nie, tutaj jest głównie na wspieraniu się i jak ktoś ma jakiś problem, to po prostu przychodzimy tacy cosplayerzy i pomagamy. Także to jest bardzo przyjazna grupka. (...) No oczywiście zdarzaja się dramy, bo to jest dosyć częste, zwłaszcza na konwentach poświęconych tematyce anime i mangi, to często sa, $z$ tego co widzę, jakieś dramy. Ale ogólnie póki co ze swojego doświadczenia nie miałam jeszcze do czynienia z dana rywalizacja" (A., 20 lat).

„Subkultura cosplayerów ciagle ewoluuje i się zmienia, niestety na gorsze. Kiedyś cosplayerzy to byta wielka rodzina, każdy szanowat każdego i zależało na wspólnej zabawie i doskonaleniu się. Teraz głównie chodzi o konkurencje, zawiść, znajomości itp." (L., 21 lat).

Cosplay i jego rozpowszechnienie określane jest przez badane osoby zdecydowanie jako szansa, ponieważ coraz więcej utalentowanych młodych ludzi decyduje się tworzyć kostiumy i się rozwijać. W ten sposób rozwija się także otoczenie społeczne cosplayerów, w skład którego wchodzi wiele in- 
dywidualnych jednostek przynależnych do różnorakich fandomów. Badane zwracają uwagę również na zagrożenia, jakie mogą pojawić się w związku z praktykowaniem cosplayu, jednak są one określane, jako dużo mniejsze, niż szanse; są też całkowicie naturalne, ponieważ tam, gdzie pojawiają się szanse, pojawiają się także zagrożenia (np. hejt podczas konkursu cosplay):

„(...) cosplay staje sie coraz bardziej popularny i dla niektórych to jest szansa, bo zawsze było takie niedoceniane hobby, a teraz mamy konkursy typu Eurocosplay, mamy wielkie konwenty typu Katsucon albo nawet nasz polski Pyrkon i dla niektórych to jest naprawdę szansa, by stać się stawnym, zarobić dużo pieniędzy, wygrać fajne nagrody. Ale z drugiej strony, jako zagrożenie... Chyba chodzi o to, że cosplay staje się już takim showbiznesem, że ludzie robia bardzo dużo rzeczy pod publikę, których normalnie prywatnie by nie zrobili, typu ocenianie, hejtowanie czyjegoś stroju, czyjegoś wygladu..." (W., 24 lata).

"Myślę, że wszędzie sa zarówno szanse, jak i zagrożenia. Jeśli zamierzasz żyć lub znaleźć się w niebezpiecznej sytuacji. Oczywiście konwenty nie sa bezpieczne w 100\%. Zawsze znajda się ludzie, którzy moga cie skrzywdzić lub manipulować toba, ale takie jest życie. Nie każdy jest dobry, ale to nie wymówka, żeby nie robić tego, co kochasz" (T., 27 lat).

„Wedtug mnie to jest szansa. Szansa przede wszystkim na pokazanie się, odważenie się, zdobycie pewności siebie oraz rozwijanie się. Przede wszystkim rozwijanie się. Cosplay to nie jest tak, że ja umiem teraz szyć płaszcz to już będa mi wychodzity wszystkie typy płaszczy. Nie, ja się będę caty czas rozwijała w tym. Cosplay to jest wieloletnia praca, nie można powiedzié, że ja umiem totalnie w cosplay, bo to jest nieprawda, cały czas się cosplayerzy rozwijaja, cały czas napotykaja różne trudności i czasami trzeba posiedzieć troszeczkę nad nimi, żeby to wyszło jakoś wszystko" (A., 20 lat).

"Myśle, że szansa dla każdego, ale także zagrożenie na cięta krytykę dzisiejszego community" (L., 21 lat).

Zdaniem badanych, cosplay i jego subkultura opierają się na samorozwoju związanym z interakcjami międzyludzkimi, na przykład poprzez udzielanie sobie wzajemnej pomocy, dzielenie się swoimi zainteresowaniami, wspieraniu się w dążeniu do wspólnego celu, jakim jest tworzenie sztuki (kostiumy, odgrywanie roli). Pomimo wysokiego indywidualizmu każdej jednostki i wielu zainteresowań oraz przynależności do różnych fandomów, cosplayerzy nawiązują przyjaźnie i potrafią ze sobą współdziałać pomimo hejtów i dram obecnych wewnątrz zbiorowości. Silne poczucie, iż wszyscy robią to co ko- 
chają i mają jeden cel dodatkowo umacnia znajomości. Istnienie wewnątrz subkultury cosplayerów wielu małych subkultur sprawia, iż pomiędzy poszczególnymi osobami swobodnie przepływają informacje dotyczące specjalistycznych metod wykonywania strojów czy rekwizytów. Początkowo formalne znajomości związane jedynie z wykonywaniem strojów następnie mogą się pogłębić i przerodzić w przyjaźnie.

\section{Znaczenie cosplayu w rozwoju zainteresowań i umiejętności}

Zagłębiając się w wywiady, zauważono, że dla osób badanych cosplay stanowi przede wszystkim kreatywne hobby, możliwość realizowania siebie i wyzwanie:

„Cosplay jest dla mnie kreatywnym hobby, bardzo rozbudowanym $i$ kształcacym w wielu dziedzinach" (W., 24 lata).

"Cosplay oznacza bycie zdolnym do przeniesienia się do mojego ulubionego fikcyjnego świata. Pozwala mi stać się czymkolwiek chcę być $i$ widzieć siebie w sposób, w jaki chcę. Oznacza także przyjaźn, stawianie sobie wyzwań i ciężka pracę" (T., 27 lat).

"Cosplay jest dla mnie takim fajnym hobby, sposobem, w którym moge pokazać siebie, wcielić się w dana postać $z$ danej animacji czy gry, serialu, filmu. Mogę w ten sposób wczuć się w rolę postaci, która widzę tylko w wirtualnym świecie. I mogę pokazać. Przy okazji rozwijam też swoje własne umiejętności" (A., 20 lat).

„Cosplay jest dla mnie czymś wyjątkowym, jest hobby, w którym utonętam po uszy, jak i moja możliwością na przyszłość, gdyż kieruję się do zawodu kostiumologa. Jest chwila zapomnienia $i$ oderwania się od rzeczywistości i tym kim jesteśmy na co dzień" (L., 21 lat).

Cosplay pozwala ludziom na rozwijanie szeregu umiejętności. Jest czasochłonny, dlatego wiąże się z ciężką pracą i stałym rozwojem posiadanych już umiejętności. Przy tworzeniu kostiumów i odgrywaniu postaci potrzeba wielu elementów, dlatego cosplay, zawierając w sobie szycie, malowanie, wykonywanie makijażu, układanie fryzur i tym podobne, wymaga od jednostek stałego doszkalania się, zdobywania informacji i rozwijania zasobów. Nie da się tworzyć dobrych kostiumów bez rozwoju umiejętności. 
Jednocześnie cosplay pozwala również na rozwój zainteresowań, ponieważ pomysły na kostiumy pochodzą przede wszystkim z kultury popularnej, która zawiera w sobie między innymi anime, mangę, komiksy, animacje, seriale, science fiction i wiele innych, na których wzorują się cosplayerzy. Aby dobrze odegrać daną postać, należy zapoznać się z jej historią, tytułami, z których pochodzi oraz ich kontekstami społecznymi, w których powstały. Zainteresowanie się jednym z elementów prowadzi często do zainteresowania kolejnym i w ten sposób do rozwoju dotychczasowych zainteresowań.

\section{Odbiór społeczny cosplayu}

Wszystkie badane odpowiadają, iż cosplayerzy są narażeni na seksizm i uprzedmiotowienie, co wynika nie tylko ze strony cosplayerów, którzy ubierają skąpe i wulgarne stroje, ale również ze strony samych fanów, którzy przekraczają granice podczas robienia zdjęć i spotkań:

„Absolutnie! Cosplay wystawia cię na oko społeczne. Kiedy już raz tego doświadczysz, zawsze będziesz uprzedmiotawiany, obojętnie od tego, jak się ubierzesz lub zachowasz. Cosplay sam w sobie nie jest problemem, ludzie sa" (T., 27 lat).

„Niestety, coraz więcej osób pokazuje się w strojach pótnagich i pokazuje, że tak właśnie wyglada cosplay, przez co cosplayerzy traca na szacunku i naraża to innych na różne podteksty i naruszenie ich osobistej przestrzeni" (L, 21 lat).

Często cosplayerzy ubierając skąpe kostiumy, sami przekonują osoby postronne, iż cosplay polega właśnie na takich aktywnościach, co powoduje, iż przestają być szanowani, a zaczynają być uprzedmiotowiani. Wystawienie „na oko społeczne" powoduje, iż cosplayerzy znajdują się pod stałą obserwacją, co może wiązać się z błędnym interpretowaniem ich zachowania, ubioru, odgrywania roli. Sami cosplayerzy zdając sobie sprawę, że są obserwowani, mogą ulegać presji lub działać pod wpływem silnego stresu.

Cosplay przez niektóre osoby odbierany jest jako synonim uprzedmiotowienia, co doprowadza do sytuacji, w których zostaje naruszana ich osobista przestrzeń. Oznacza to, iż z jednej strony coraz więcej osób interesuje się cosplayem i odbiera go jako przyjazną lub neutralną subkulturę, natomiast z drugiej spotykają się z wieloma utrudnieniami i seksizmem, co negatywnie wpływa na społeczne postrzeganie cosplayu przez osoby zainteresowane, jak i postronne. 


\section{Trudności techniczne, z jakimi spotykają się cosplayerzy podczas przygotowywania kostiumów}

Cosplayerzy często spotykają się z wieloma problemami podczas przygotowywania strojów. Największe dotyczą wykonywania stelaży oraz określenia proporcji, w jakich należy przygotować kostium. Zdarzają się również, zwłaszcza początkującym cosplayerom, problemy z brakiem odpowiednich narzędzi i elementów potrzebnych do wykonania strojów:

„Wyzwaniami sa zawsze podstawy konstrukcyjne. Zawsze staram się nauczyć nowych rzeczy, dlatego czasami wybieram jakaś postać, ponieważ będzie ona stanowić wyzwanie i pozwoli mi się czegoś nauczyć" (T., 27 lat).

„Ze wszystkimi! Po prostu tu raz coś się zepsuje, tutaj raz coś przypadkowo skleję, przypadkowo cyjanoakrylem, a dość często kończy się na tym, że mam posklejane nawet palce ze sobą. Ogólnie, tak technicznie no to czasami brakuje mi jakichś materiałów, czasami coś zepsuje uważając na dany materiat, ale i tak zepsuję. Najwięcej miałam takich problemów z Rebellionem, czyli mieczem Dantego, ponieważ on zostat stworzony w całości z pianki evy, zostat on usztywniony listwa drewniana $i$ te listwe przykleiłam niestety krzywo. Myślałam, że jest prosto, a przykleiłam krzywo tak, że miecza nie mogę trzymać gdziekolwiek chcę na rękojeści, tylko muszę w jednym miejscu, po prostu, żeby to nie pękło. Tak, że myśle, że to był taki największy problem. Bo też nie kupiłam jednej dtugości tej listwy tylko kupiłam dwie różne tak, że to jest taki jeden problem. Kolejnym problemem może być to, że na przykład ciepty klej po prostu nie chce mi się załadować, żeby zaczą mi się rozpuszczać ten klej. I czasami się zapycha i potrzebuje pomocy taty, żeby to odetkać" (A., 20 lat).

„Na pewno trudne jest dla mnie robienie jakichkolwiek technicznych stelaży itp. z powodu braku odpowiednich narzędzi. Często też w cosplayu ciężkie jest odpowiednie proporcjonowanie [dobieranie odpowiednich proporcji - przyp. autora] stroju do naszego ciała z powodu nierealnych postur postaci z gier itp." (L., 21 lat)

Jak podkreślają niektórzy cosplayerzy, wybierają oni postaci stanowiące wyzwanie, ponieważ pozwoli im to czegoś się nauczyć, zdobyć nowe umiejętności, które następnie zostaną wykorzystane do konstrukcji bardziej skomplikowanych kostiumów i elementów. W rezultacie spowoduje, iż wykonywanie kostiumów będzie bardziej sprawne, a poprzednie trudności usunięte.

Konstruowanie strojów wiąże się między innymi z potrzebą pomocy, zarówno bliskich osób, jak i nowo poznanych cosplayerów oraz wykonawców rekwizytów, na przykład poprzez fora internetowe lub aplikacje ${ }^{22}$.

${ }^{22}$ Istnieje wiele forów, na których cosplayerzy mogą zasięgnąc pomocy i rady podczas wytwarzania kostiumów; w latach 2014 - 2017 słynna była również aplikacja pomagająca w upo- 
Zdaje się, iż cechą charakterystyczną cosplayerów jest tak zwane „,uczenie się na błędach", czyli wykonywanie pewnych elementów samodzielnie lub z niewielką pomocą osób trzecich, aby nabrać umiejętności, które w późniejszym czasie przydadzą się do wykonania lepszych elementów, bez poprzednich niedociągnięć.

Ponadto, dopiero obcowanie z wykonywaniem kostiumów pozwala na określenie odpowiedniego typu narzędzi i zaopatrzenie się $\mathrm{w}$ nie po czasie, co znacznie usprawnia i ułatwia konstruowanie stelaży, replik i elementów niezbędnych do tego, aby prawidłowo odegrać rolę danej postaci.

\section{Znaczenie wcielania się w rolę w cosplayu}

Okazało się ono naturalną konsekwencją cosplayu w trzech przypadkach; można również zauważyć zobowiązanie względem publiki:

„Czuje się dokładnie tak samo, jak ja, ale lepiej. O ile to ma jakiś sens" (T., 27 lat).

„Jak się czuję? Czuję się tak jaby wyjątkowa. Ponieważ wcielam się w ta postać i czuje, że mam też duże wyzwanie przed soba, ponieważ muszę pokazać właśnie ludziom z jak najlepszej strony siebie, jako dana postać. Nie pomylić się w niczym. Po prostu... Dziwnie by wygladało, jakbym nagle, przykładowo biorac np. mojego Dantego i pokazać go jako takiego mężczyznę, mimo że stworzyłam damska wersję, jako takiego mężczyznę, który cieszy się wszystkim, który mógłby nosić ubranka w kolorze tęczy, także... No właśnie... Rozumiesz tę cała abstrakcję. Także przede wszystkim czuje taki obowiazek jakby i też wiem, że musze sama na siebie uważać, żeby wczuć sie odpowiednio w dana postać. (...) Dokładnie. Tak będzie, np. z Little Sister. Bo z Little Sister znowu będę... Wiem, że będę mogła przekazać jakby wszystkie takie swoje emocje i to będę po prostu naturalna ja. W sensie, że chodzi mi głównie o to, że Little Sister jest osoba, która jak - zwłaszcza sie ja uratuje od tego ADAMu - to ona jest taka strachliwa. Dziękuje temu, który ją uratowat i po prostu biegnie, bo ona chce po prostu uciec od tego całego złego świata. I to jest... Czasami też mam takie momenty, że bym po prostu chciała... Gdy coś się dzieje to bym po prostu chciała uciec tak, że myśle, że w tym podpasuję do niej" (A., 20 lat).

„Niewyobrażalnie wspaniale, kocham wychodzić na scene i być ta postacia dla wszystkich widzów" (L., 21 lat).

Wcielenie się $\mathrm{w}$ wybraną rolę spowodowało u badanych lepsze samopoczucie - czują się jak „lepsza wersja” samej siebie; cosplayerki opisując uczu-

rządkowaniu wybranych postaci, elementów ich stroju, a także (w przybliżeniu) kosztu całego kostiumu - do dzisiaj dostępna jest zarówno w Sklepie Play, jak i w formie strony internetowej pod adresem: http://www.cosplanner.net/\# 
cia związane $\mathrm{z}$ wcielaniem się $\mathrm{w}$ role, wyrażają się wyłącznie $\mathrm{w}$ superlatywach, mówiąc, iż to pozwala im na poczucie się kimś wyjątkowym.

$\mathrm{W}$ wypowiedziach wybrzmiewa również wysokie poczucie odpowiedzialności za odgrywaną postać - badane zdają sobie sprawę, iż publika oczekuje od nich dokładnego odgrywania roli, ponieważ - oprócz kostiumu - to, co sprawia, iż dana postać to właśnie ona, to specyficzna maniera zachowania, mimika, gestykulacja i tym podobne. Są to elementy związane $\mathrm{z}$ role-playem, który stanowi jedną z centralnych kategorii cosplayu.

Aspekt wcielania się w rolę pozwala nie tylko na poczucie się kimś wyjątkowym, ale również umożliwia pokazanie się z lepszej strony, bycie lepszym; jak gdyby stanowi szansę na pokazanie pozytywnych stron, które w rzeczywistości są tłumione lub niewyraźne. Jeśli dane cechy (spryt, inteligencja, uczciwość, odwaga) zostaną docenione w momencie, w którym jednostka podejmuje się odegrania roli, być może wpłynie to pozytywnie na samoocenę cosplayerki i spowoduje uwydatnienie się tych cech w rzeczywistości.

\section{Znaczenie cosplayu dla poczucia tożsamości}

Pytanie o znaczenie cosplayu dla poczucia tożsamości okazało się dla badanych skomplikowanym zagadnieniem:

"Cosplay też jest forma sztuki, więc jak najbardziej można wyrażać siebie przez niego. Aczkolwiek dla mnie to jest wcią̇ po prostu przebieranie się, więc raczej nie powiem na ten temat nic kreatywnego" (W., 24 lata).

"Nie wiem jak duży wptyw może mieć, ale na pewno rzuca światło na to, jaka ktoś jest osobą. Cosplay może pokazać ci rzeczy, o które wcześniej byś siebie nawet nie podejrzewat. Stanie się kimś innym i patrzenie na siebie przez pryzmat tej postaci może pomóc ci zrozumieć siebie" (T., 27 lat).

„Bardzo trudne pytanie! (...) Czy może mieć...? Myślę, że to w sumie zależy od człowieka, bo ja przywiazuję do cosplayu taka wagę, że wcielam się w postać tak, jakbym odgrywata jakiś spektakl teatralny, że jestem dana postacia. Niestety na chwilę. Bardzo żatuję, bo chciałabym być dana postacia. Każdy by chciał zostać taka postacia, w którą się wciela, na zawsze. Ale jakoś tak, jest event, jestem dana postacia, kończy się event, kończę być ta postacia i jeżeli ktoś miatby z tym problem, to nie wiem jakby to... Jakbym mogła zareagować na coś takiego. Nie potrafię odpowiedzieć do końca na to pytanie" (A., 20 lat). 
„Tak może mieć, ale to wszystko zależy od osoby i jej psychiki. Niektórzy uciekaja w ten sposób od realnego życia, a inni czerpia z tego przyjemność na moment, ale nie żyja tym na co dzień. W cosplayu każdy może być kim chce" (L., 21 lat).

Badane postrzegają cosplay jako coś, co może mieć wpływ na kształtowanie się tożsamości, jednak jest to zależne od danej osoby. Zazwyczaj wcielanie się w rolę stanowi sposób na ucieczkę od trudności życia codziennego; wcielanie się w wybraną postać może pokazać jednostce coś, czego sama o sobie do tej pory nie wiedziała i w ten sposób doprowadzić do ukształtowania w pewien sposób tożsamości tejże jednostki.

W wypowiedzi pojawiła się obawa o niemożność wyjścia z roli, która stanowiłaby sytuację trudną, skomplikowaną do tego stopnia, iż wypowiadająca się osoba nie wiedziałaby, w jaki sposób powinna zareagować.

Cosplay stanowi zjawisko, w którym każdy dowolnie może wybierać postać, a więc decydować, kim chce być w danym momencie. Oznacza to, iż dowolnie może również wybierać cechy charakteru i sposób zachowania, jaki chce zaprezentować; cechy te mogą być zbieżne z cechami charakteru posiadanymi przez jednostkę lub stanowić ich przeciwieństwo. Umożliwia to sprawdzenie danej osobie, jak czułaby się będąc kimś innym lub rozwijając się jako osoba bardziej otwarta, pewna siebie, dumna i tym podobnie. Dostęp do odmienności i sprawdzenie jej w bezpośrednim kontakcie może zmienić postrzeganie samego siebie i $\mathrm{w}$ rezultacie doprowadzić do zmian w tożsamości oraz ją ukształtować.

\section{Podsumowanie}

Badane postrzegają cosplay jako istotną część swojego życia, stanowiącą nie tylko hobby, ale rzutującą na wiele aspektów, takich jak otoczenie społeczne i związki interpersonalne. Cosplay daje im możliwość rozwoju umiejętności i zainteresowań, mierzenia się z problemami i stawiania czoła przeciwnościom. Jest to również płaszczyzna, na której dwie badane budują swoje doświadczenia zawodowe.

W miarę rozwoju zjawiska pojawiają się także nowe problemy, z którymi cosplayerki się spotykają, a dotyczące trudności technicznych i nieporozumień międzyludzkich. Nie zraża ich to jednak, ponieważ robienie tego co kochają i wspaniałe uczucia towarzyszące wcielaniu się w rolę rekompensują niemal każdą trudność, z jaką się spotykają.

Cosplay pomaga również w ucieczce od codziennych problemów i lepszym rozumieniu siebie, co odnosi pozytywne skutki w kształtowaniu tożsamości. 
W trakcie analizowania wywiadów wyłaniają się również cztery komponenty cosplayu wyodrębnione przez Winge ${ }^{23}$, którymi są: cosplayer, otoczenie społeczne, postać i role play oraz kostium.

$\mathrm{W}$ procesie wychowania pedagodzy spotykają się z wieloma metodami i formami (technikami) pracy wychowawczej. Jednymi z nich są formy oparte na oddziaływaniach niewerbalnych, w których skład wchodzą takie, jak improwizowana dramatyzacja, trening relaksacyjny, swobodna ekspresja plastyczna, muzykoterapia, czy zabawa $w$ teatr $^{24}$. Niemal każdy $z$ tych elementów może zostać połączony z cosplayem i być zastosowany jako nowa technika oddziaływania na podopiecznych. Pomimo trudności, jakie sprawiło badanym pytanie o kwestię tożsamości i jej kształtowania poprzez cosplay, wskazały one, iż cosplay może mieć pewien związek z formowaniem się tożsamości adolescentów, a więc stanowić jedną z potencjalnych technik, dzięki której pedagodzy będą mogli pokierować procesem kształtowania tożsamości nastolatków. Wymaga to jednak pogłębionych badań i stworzenia odpowiedniego programu, dzięki któremu cosplay będzie możliwy do zaimplementowania w rzeczywistości szkolnej.

Uwagę moją zwraca również kwestia tak zwanej tożsamości negatywnej ${ }^{25}$, która teoretycznie mogłaby zostać nieco złagodzona poprzez odegranie roli zmarginalizowanej postaci. Dzięki takiej aktywności adolescent byłby W stanie przyswoić wiele korzyści z przyjęcia tożsamości negatywnejej ${ }^{26}$, bez faktycznego jej przyjmowania $w$ warunkach niekontrolowanych.

W rozmowie o cosplayu należy zwrócić baczną uwagę również na aspekt pedagogiki kultury popularnej, ponieważ „,współcześnie kultura popularna przestaje być postrzegana jako »pan Hyde« przestrzeni kulturowej, ale jako ważny obszar edukacji nieformalnej"27. Jeśli ujmiemy w ten sposób kulturę popularną, pedagodzy otrzymają nowy obszar oddziaływań, który pozwoli im nie tylko nawiązać lepszy kontakt z podopiecznymi, ale również uatrakcyjnić swoje zajęcia.

Cosplay, w wyniku specjalnie przygotowanych programów, może stanowić element wychowawczy, w którym pedagodzy i adolescenci znajdą „wspólny język”, dzięki któremu możliwe będzie wykorzystanie tak kultury popularnej, jak i technik wychowawczych opartych na oddziaływaniach niewerbalnych.

${ }^{23}$ Patrz wyżej: Czym jest cosplay?

${ }^{24}$ L. Zarzecki, Teoretyczne podstawy wychowania. Teoria i praktyka w zarysie, Jelenia Góra 2012, s. 98.

25 A. Brzezińska, Psychologia rozwoju człowieka, s. 280-284.

${ }^{26}$ S. Hejmanowski za: tamże, s. 281.

${ }^{27}$ W. Jakubowski, Pedagogika kultury popularnej - teorie, metody i obszary badań, Kraków 2017, s. 10. 


\section{BIBLIOGRAFIA}

Babbie E., Badania społeczne w praktyce, Warszawa, 2004.

Brzezińska A., Psychologia rozwoju człowieka, Sopot, 2016.

Gerbasi K.C., Plante C.N., Reysen S., Roberts S.E., "Coming Out” as an Anime Fan: Cosplayers in the Anime Fandom, Fan Disclosure, and Well-Being, The Phoenix Papers, USA, 2018.

Hill N.L., Embodying Cosplay: Fandom Communities in the USA, Georgia State University, 2017.

http:/ / www.cosplanner.net/\#, hasło cosplanner, [dostęp: 05.05.2020].

Ito M., Okabe D., Tsuji I., Fandom Unbound: Otaku Culture in a Connected World, New Haven - London 2012.

Jakubowski W., Pedagogika kultury popularnej - teorie, metody i obszary badań, Kraków 2017.

Langsford C., Cosplay in Australia: (Re)creation and Creativity Assemblage and Negotiation in a Material and Performative Practice, Adelaide 2014.

Lotecki A., Cosplay Culture: The Development of Interactive and Living Art Throught Play, Toronto - Ontario 2012.

Pilch T., Bauman T., Zasady badań pedagogicznych Strategie ilościowe i jakościowe, Warszawa 2001.

Rahman O., "Lolita": Imaginative Self and Elusive Consumption, [w:] Fashion Theory, The Journal of Dress Body \& Culture, 2011.

Rahman O., "Cosplay": Imaginative Self and Performing Identity, [w:] Fashione Theory, The Journal of Dress Body \& Culture, 2012.

Winge T., Costuming the Imagination: Origins of Anime and Manga Cosplay, Mechademia, 2006, 1.

Wrona D., Cosplay a role-play [w:] Nauczyciel i uczeń w przestrzeni społecznej, red. A. Borzęcka, A. Twaróg-Kanus, R. Waluś, Kraków 2019.

Wrona D., Cosplay jako fenomen kulturowy. Konteksty pedagogiczne i społeczno-kulturowe (praca magisterska napisana pod kierunkiem Prof. dr hab. A. Gromkowskiej-Melosik), Uniwersytet im. Adama Mickiewicza, Poznań 2018.

Zarzecki L., Teoretyczne podstawy wychowania Teoria i praktyka w zarysie, Jelenia Góra 2012. 